\title{
Interferon Therapy Exacerbated Pulmonary Hypertension in a Patient with Hepatitis C Virus Infection: Pathogenic Interplay among Multiple Risk Factors
}

\author{
Hiromi Tsuchiya ${ }^{1,2}$, Hidetaka Kioka ${ }^{1}$, Kentaro Ozu ${ }^{1}$, Tomohito Ohtani ${ }^{1}$, Osamu Yamaguchi ${ }^{1}$, \\ Yoshikazu Yazaki ${ }^{2}$, Keiko Yamauchi-Takihara ${ }^{1,3}$ and Yasushi Sakata ${ }^{1}$
}

\begin{abstract}
Pulmonary arterial hypertension (PAH) is known to develop as a consequence of multiple genetic and/or non-genetic factors. A 27-year-old woman with chronic hepatitis C virus (HCV) infection developed severe PAH after interferon (IFN) therapy. Although most of the reported clinical courses of IFN-induced PAH are poor despite the discontinuation of IFN, the present patient was successfully treated with a triple combination therapy. In this report, we discuss the crosstalk among chronic HCV infection, IFN therapy, autoimmune disorders, and portal hypertension in the pathogenesis and development of PAH.
\end{abstract}

Key words: portopulmonary hypertension, $\mathrm{HCV}$ infection, interferon therapy, up-front combination therapy

(Intern Med 56: 1061-1065, 2017)

(DOI: 10.2169/internalmedicine.56.7822)

\begin{abstract}
Introduction
Pulmonary hypertension $(\mathrm{PH})$ is defined as a mean pulmonary artery pressure (PAP) of $\geq 25 \mathrm{mmHg}$ with right heart catheterization (RHC) (1) and is classified into 5 groups according to the clinical presentation, pathological findings, and hemodynamic characteristics. Drug-induced PH and portal hypertension-associated $\mathrm{PH}$ are both categorized into Group 1 PH-pulmonary arterial hypertension (PAH). Multiple genetic and/or non-genetic factors have been reported to contribute to the pathogenesis of PAH (2). Interferon (IFN) is a drug that has been suggested to elevate the risk of developing PAH. Furthermore, chronic inflammation caused by viral infection or autoimmune disease and a female gender are also known risk factors for PAH (3).

In this report, we describe a female case of PAH associated with IFN therapy, portal hypertension, a chronic hepatitis $\mathrm{C}$ virus (HCV) infection, and an autoimmune disorder/reaction who presented with multiple triggers, which might have contributed to the development of PAH.
\end{abstract}

\section{Case Report}

\begin{abstract}
Case Report
A 27-year-old woman was admitted to a general medical
center because of worsening dyspnea on exertion in Decem-
ber 2014. She had a history of chronic HCV infection
(genotype 1b) and Hashimoto's thyroiditis. Her mother was
diagnosed with liver cirrhosis and an HCV infection, so the
HCV may have been transmitted vertically from her mother.
She was treated with pegylated IFN- $\alpha$ therapy for the HCV
infection for 2 months prior to admission. Although the IFN
therapy was successful in treating the sustained viral re-
sponse, she presented with a cough and dyspnea on exertion
after the initiation of the IFN therapy. Her symptoms gradu-
ally worsened, and she was WHO functional class III on ad-
mission.
Her chest radiography revealed dilatation of the pulmo-
nary artery and bilateral pleural effusions (Fig. 1A), and a
dominant R wave in lead V1 on electrocardiogram (ECG)
indicated right ventricular hypertrophy (Fig. 1B). Doppler
echocardiography revealed severe tricuspid regurgitation
with a tricuspid regurgitation pressure gradient (TRPG) of
A 27-year-old woman was admitted to a general medical center because of worsening dyspnea on exertion in December 2014. She had a history of chronic HCV infection (genotype 1b) and Hashimoto's thyroiditis. Her mother was diagnosed with liver cirrhosis and an HCV infection, so the HCV may have been transmitted vertically from her mother. She was treated with pegylated IFN- $\alpha$ therapy for the HCV infection for 2 months prior to admission. Although the IFN therapy was successful in treating the sustained viral response, she presented with a cough and dyspnea on exertion after the initiation of the IFN therapy. Her symptoms gradually worsened, and she was WHO functional class III on admission.

Her chest radiography revealed dilatation of the pulmonary artery and bilateral pleural effusions (Fig. 1A), and a dominant $\mathrm{R}$ wave in lead V1 on electrocardiogram (ECG) indicated right ventricular hypertrophy (Fig. 1B). Doppler with a tricuspid regurgitation pressure gradient (TRPG) of
\end{abstract}

\footnotetext{
${ }^{1}$ Department of Cardiovascular Medicine, Osaka University Graduate School of Medicine, Japan, ${ }^{2}$ Department of Cardiovascular Medicine, Saku General Hospital Advanced Care Center, Japan and ${ }^{3}$ Health Care Center, Osaka University, Japan 

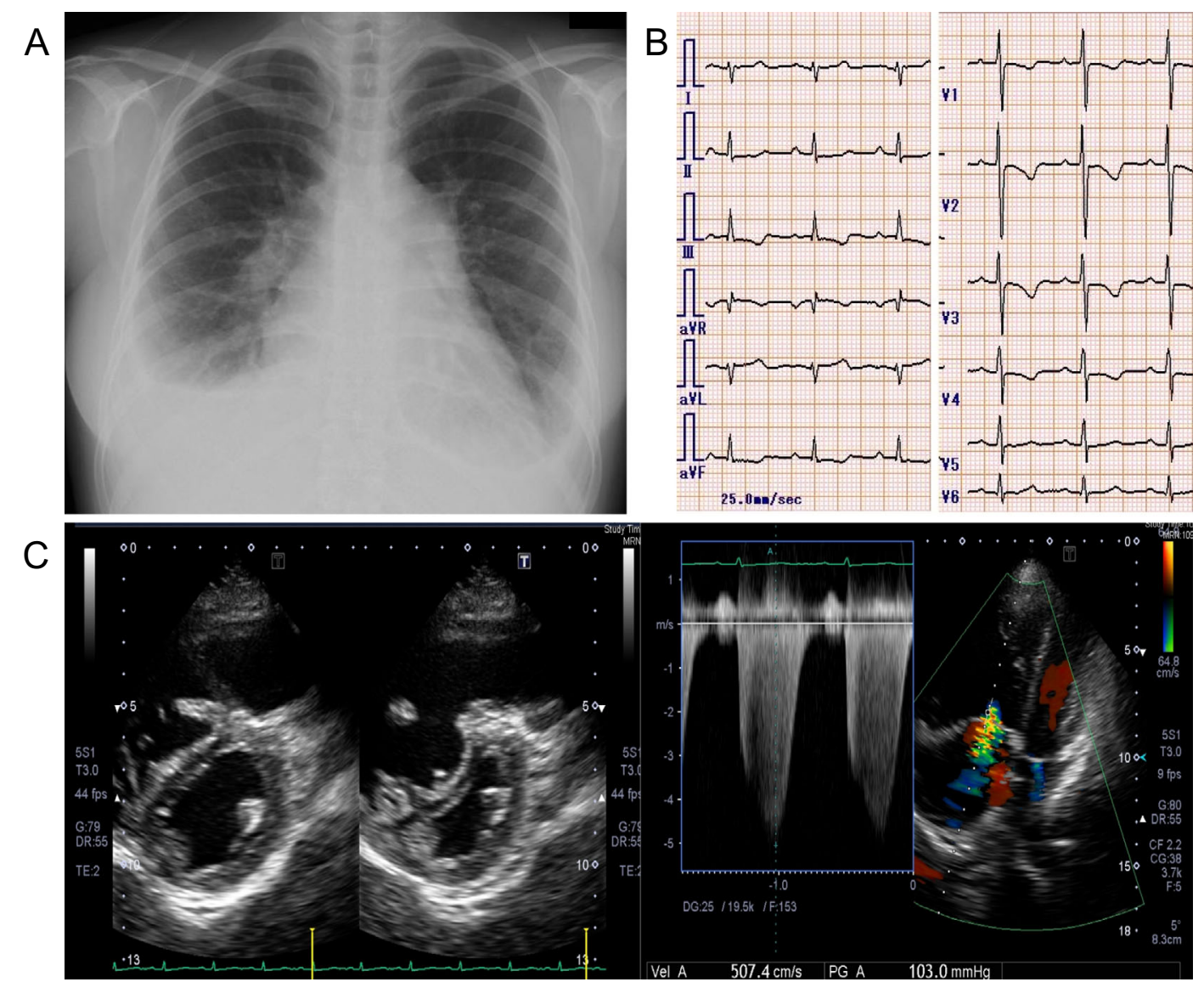

Figure 1. Chest radiography, electrocardiogram, and echocardiography on admission. A: Chest radiography reveals dilatation of the pulmonary artery, bilateral pleural effusions, and enlargement of the heart. B: Electrocardiogram suggests right ventricular hypertrophy. C: Doppler echocardiography shows flattening of the interventricular septum (left panel) and severe tricuspid regurgitation with a tricuspid regurgitation pressure gradient (TRPG) of $>100 \mathrm{mmHg}$ (right panel).

Table 1. Summary of Right Heart Catheterization (RHC).

\begin{tabular}{lllll}
\hline & $1^{\text {st }}$ RHC & $2^{\text {nd }}$ RHC & $3^{\text {rd }}$ RHC & $4^{\text {th }}$ RHC \\
& Dec. 10, 2014 & Jan. 29, 2015 & Mar. 12, 2015 & Jul. 14, 2015 \\
\hline HR (bpm) & 89 & 90 & 73 & 52 \\
BP (mmHg) & $114 / 61$ & $94 / 38$ & $99 / 47$ & $101 / 58$ \\
PAWP (mmHg) & 10 & 16 & 13 & 13 \\
RAP (mmHg) & 6 & 11 & 8 & 11 \\
PAP (mmHg) & $101 / 44 / 63$ & $63 / 23 / 42$ & $53 / 14 / 33$ & $50 / 19 / 31$ \\
CO (L/min) & 4.5 & 12.7 & 10.9 & 6.96 \\
CI (L/min/m $\left.{ }^{2}\right)$ & 2.9 & 7.8 & 6.9 & 4.3 \\
PVR (Wood units) & 11.8 & 2.3 & 2.8 & 2.6 \\
\hline
\end{tabular}

HR: Heart rate, BP: Blood pressure, PAWP: Pulmonary arterial wedge pressure, RAP: Right atrial pressure, PAP: Pulmonary artery pressure, CO: Cardiac output, CI: Cardiac index, PVR: Pulmonary vascular resistance

$>100 \mathrm{mmHg}$ and flattening of the interventricular septum, suggesting severe PH (Fig. 1C). RHC on the day of admission (December 10, 2014) confirmed an elevated PAP and pulmonary vascular resistance (PVR) with a normal pulmonary artery wedge pressure (Table 1 ). IFN-induced PAH was thus suspected, and the IFN therapy was immediately discontinued. A triple combination therapy with epoprostenol
(2 ng/kg/min), ambrisentan (5 mg/day), and tadarafil (20 $\mathrm{mg}$ /day) was started within 3 days of admission. However, the epoprostenol was discontinued because of a headache. The tadarafil was increased from $20 \mathrm{mg} /$ day to $40 \mathrm{mg}$ /day, and beraprost (120 $\mu \mathrm{g} /$ day) was added instead of epoprostenol.

A second RHC was performed one and a half months af- 
A

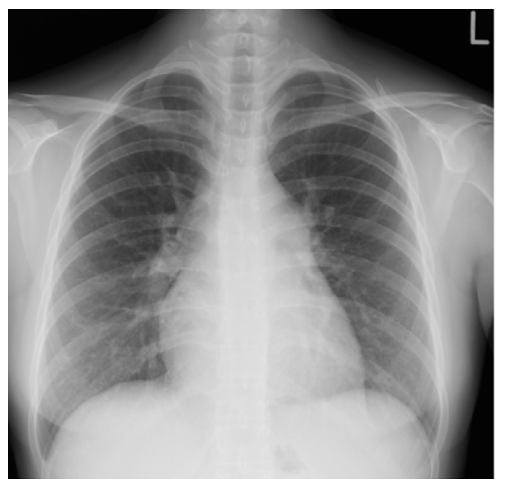

B
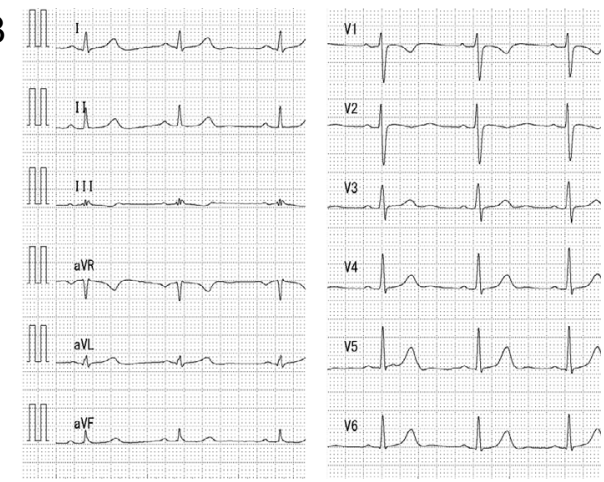

C

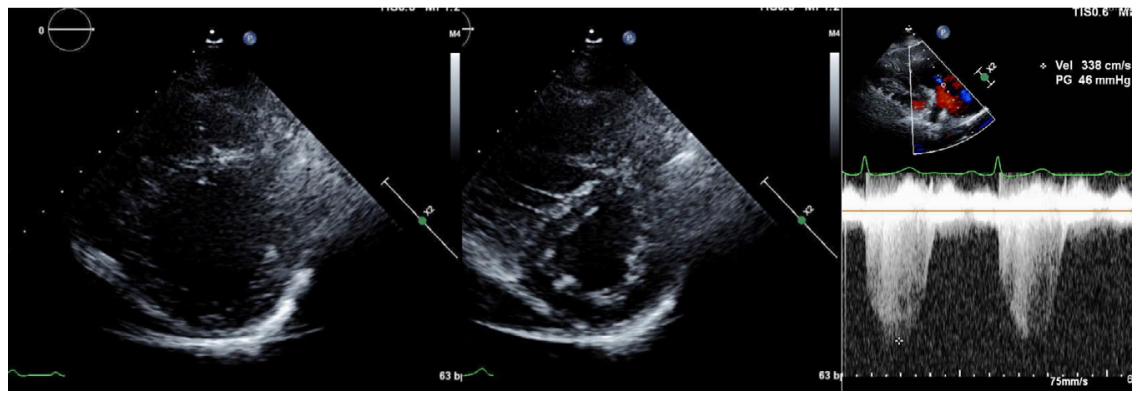

Figure 2. Chest radiography, electrocardiogram, and echocardiography during the chronic phase (7 months after admission). A: Chest radiography shows mild pulmonary artery dilatation without any pleural effusion. B: Electrocardiogram shows no sign of right ventricular hypertrophy. C: Doppler echocardiography shows mild flattening of the interventricular septum and mild tricuspid regurgitation with a tricuspid regurgitation pressure gradient (TRPG) of $46 \mathrm{mmHg}$.

ter the discontinuation of the IFN and starting the administration of pulmonary vasodilators, revealing a decreased PAP (from 101/44/63 to 63/24/42 $\mathrm{mmHg}$ ) and PVR (from 11.8 to 2.3 Wood units) and an increased cardiac output (CO) (from 4.5 to $12.7 \mathrm{~L} / \mathrm{min}$ ). Her respiratory condition gradually improved, although her PAP was still high.

Considering her medical history and clinical course, IFNinduced PAH was suspected. Serological tests were positive for anti-ds-DNA antibody, which suggested the concomitant involvement of connective tissue disease-associated PAH. She was therefore transferred to our hospital for further assessment of PAH in March 2015. On a physical examination, a Levine 3/6 systolic murmur was detected at the 5th intercostal space by the right sternal border. An abdominal examination revealed hepatosplenomegaly. A peripheral examination revealed no pedal edema. She had no characteristic findings of connective tissue diseases such as a skin rash on the face, joint pain, a low-grade fever, or Raynaud's phenomenon. Furthermore, the anti-ds-DNA antibodies turned negative (Table 2), suggesting transient immunomodulation by the IFN.

Abdominal ultrasonography and computed tomography (CT) suggested chronic liver disease with splenomegaly. A liver biopsy was performed for further assessment of the chronic liver disease, and F4 stage fibrosis (liver cirrhosis) was revealed. A ventilation/perfusion lung scan showed no significant mismatch. High-resolution CT did not show any signs of interstitial lung disease or emphysema.

A decrease in the PAP $(53 / 14 / 33 \mathrm{mmHg})$ was observed during the third RHC (Table 1). The oximetry run during the RHC did not suggest left-to-right intracardiac shunts. An elevated PAP and high $\mathrm{CO}$ indicated portopulmonary hypertension (POPH). The IFN might have triggered an acute worsening of POPH. A fourth RHC performed 7 months after the interruption of the IFN therapy indicated further hemodynamic improvement as follows: PAP 50/19/31 $\mathrm{mmHg}, \mathrm{CO} 6.96 \mathrm{~L} / \mathrm{min}$, CI $3.63 \mathrm{~L} / \mathrm{min} / \mathrm{m}^{2}$, and PVR 2.6 Wood units (Table 1). The results of chest radiography, ECG, and echocardiography also suggested an improvement in her PH (Fig. 2). She was stable in WHO functional class II with combination therapy of ambrisentan (5 mg/day), tadarafil (40 mg/day), and beraprost (120 $\mu \mathrm{g} /$ day).

\section{Discussion}

In this report, we described a woman with vertically transmitted chronic HCV infection and autoimmune thyroiditis in whom IFN therapy induced a worsening of POPH. This case highlights the contribution of multiple risk factors in triggering and developing $\mathrm{PH}$ (Fig. 3).

A clinical classification of $\mathrm{PH}$ was established by categorizing $\mathrm{PH}$ into 5 groups, which share similar pathological and hemodynamic characteristics $(3,4)$. Drug- and toxininduced $\mathrm{PH}$ and $\mathrm{POPH}$ are both categorized into Group 1 (i.e. PAH). A number of drugs and toxins have been identified as risk factors for the development of PAH. They are categorized according to the strength of the available evidence to this end as "definite", "likely", and "possible". IFN is listed as a "possible" risk factor (4).

IFN has growth regulatory properties and a wide variety 


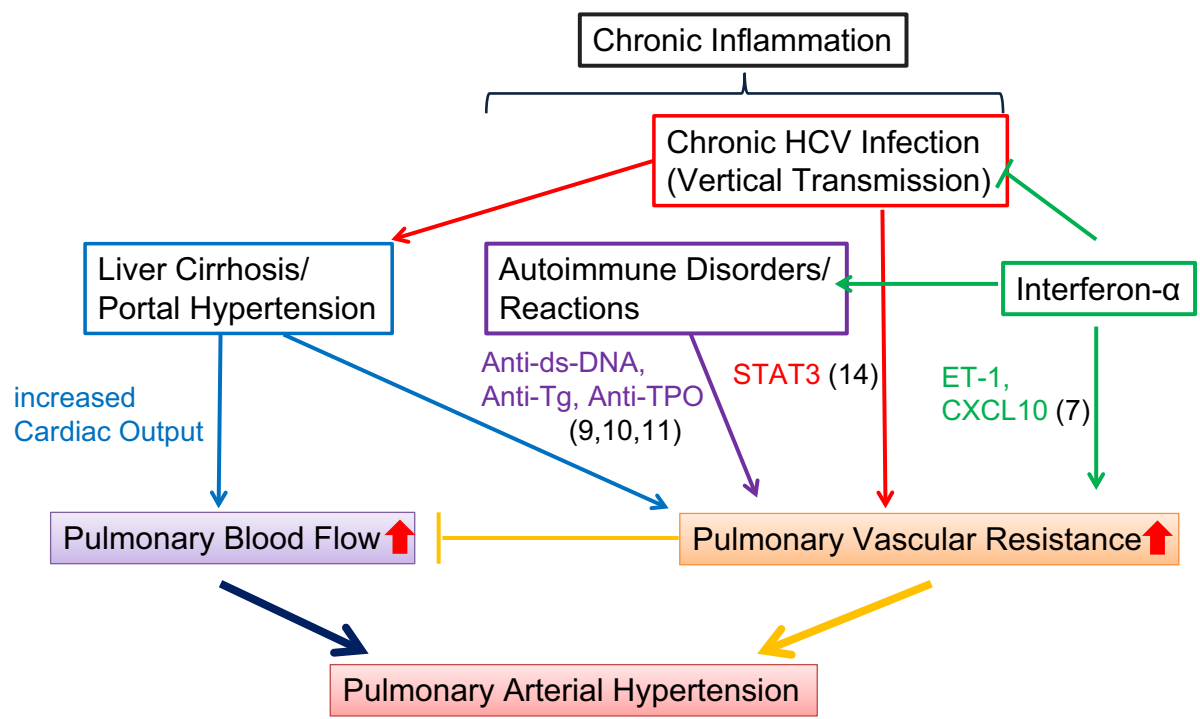

Figure 3. Pathogenic interplay among multiple risk factors for PAH. A schematic representation of the pathogenic interplay among chronic HCV infection, IFN, liver cirrhosis/portal hypertension, and autoimmune disorders/reactions for the development and worsening of pulmonary arterial hypertension. HCV: Hepatitis C virus, IFN: interferon, Anti-ds-DNA: Anti-double strand-deoxyribonucleic acid, Anti-Tg: Anti-thyroglobulin, Anti-TPO: Anti-thyroperoxidase, ET-1: Endothelin-1, CXCL10: Chemokine ligand 10

Table 2. Laboratory Findings on Mar. 12, 2015.

\begin{tabular}{|c|c|c|c|c|c|}
\hline WBC & $3,289 / \mu \mathrm{L}$ & $\mathrm{TP}$ & $5.3 \mathrm{~g} / \mathrm{dL}$ & $\mathrm{Tg} \mathrm{Ab}$ & $211 \mathrm{IU} / \mathrm{mL}$ \\
\hline $\mathrm{Hb}$ & $9.8 \mathrm{~g} / \mathrm{dL}$ & Alb & $4.0 \mathrm{~g} / \mathrm{dL}$ & TPO Ab & $7.1 \mathrm{IU} / \mathrm{mL}$ \\
\hline Hct & $30.1 \%$ & $\mathrm{CK}$ & $30 \mathrm{IU} / \mathrm{L}$ & ds-DNA Ab & $<2 \mathrm{IU} / \mathrm{mL}$ \\
\hline Plt & $17.5 \times 10^{3} / \mu \mathrm{L}$ & KL-6 & $160 \mathrm{IU} / \mathrm{L}$ & ACL- $\beta 2 \mathrm{GPI}$ & $<8 \mathrm{IU} / \mathrm{mL}$ \\
\hline & & CRP & $0.07 \mathrm{mg} / \mathrm{dL}$ & $\mathrm{RF}$ & $<10 \mathrm{IU} / \mathrm{mL}$ \\
\hline $\mathrm{Na}$ & $139 \mathrm{mEq} / \mathrm{L}$ & & & & \\
\hline K & $3.8 \mathrm{mEq} / \mathrm{L}$ & PT-INR & 1.20 & HBs-Ag & $(-)$ \\
\hline $\mathrm{Cl}$ & $106 \mathrm{mEq} / \mathrm{L}$ & APTT & $34.5 \mathrm{sec}$ & HBs-Ab & $(-)$ \\
\hline BUN & $18.7 \mathrm{mg} / \mathrm{dL}$ & Fibrinogen & $202 \mathrm{mg} / \mathrm{dL}$ & $\mathrm{HCV}-\mathrm{Ab}$ & $(+)$ \\
\hline Cre & $0.97 \mathrm{mg} / \mathrm{dL}$ & FDP & $1.6 \mu \mathrm{g} / \mathrm{mL}$ & HCV-RNA & $(-)$ \\
\hline eGFR & $70 \mathrm{~mL} / \mathrm{min}$ & D-dimer & $0.27 \mu \mathrm{g} / \mathrm{mL}$ & HIV & $(-)$ \\
\hline T-Bil & $0.9 \mathrm{mg} / \mathrm{dL}$ & Protein S & $78 \%$ & & \\
\hline AST & $25 \mathrm{IU} / \mathrm{L}$ & Protein $\mathrm{C}$ & $60 \%$ & \multicolumn{2}{|c|}{ Blood gas analysis (room air) } \\
\hline ALT & $7 \mathrm{IU} / \mathrm{L}$ & & & $\mathrm{pH}$ & 7.467 \\
\hline LDH & $190 \mathrm{IU} / \mathrm{L}$ & $\mathrm{BNP}$ & $71.7 \mathrm{pg} / \mathrm{mL}$ & $\mathrm{pCO}_{2}$ & $35.0 \mathrm{mmHg}$ \\
\hline ALP & 184 IU/L & TSH & $5.11 \mu \mathrm{IU} / \mathrm{mL}$ & $\mathrm{pO}_{2}$ & $88 \mathrm{mmHg}$ \\
\hline$\gamma$-GTP & 43 IU/L & FT4 & $0.8 \mathrm{ng} / \mathrm{dL}$ & $\mathrm{HCO}_{3}^{-}$ & $24.6 \mathrm{mEq} / \mathrm{L}$ \\
\hline UA & $3.0 \mathrm{mg} / \mathrm{dL}$ & FT3 & $2.8 \mathrm{pg} / \mathrm{mL}$ & $\mathrm{BE}$ & $0.8 \mathrm{mmol} / \mathrm{dL}$ \\
\hline
\end{tabular}

of immunomodulatory activities and exerts antiviral activity, inhibitory effects on angiogenesis, a regulatory effect on cell differentiation. There are several case reports that have suggested a pathogenic role of IFN in the development of PAH $(5,6)$. George et al. reported a possible molecular mechanism by which IFN may mediate the development of PAH via activation of interferon $\gamma$ inducible protein 10 (IP 10; CXCL10) and endothelin-1 (ET-1) (7). However, most patients diagnosed with IFN-induced $\mathrm{PAH}$ in a French registry and some case reports have described the association of other risk factors with $\mathrm{PAH}$, such as portal hypertension and/or human immunodeficiency virus infection (8). In this case, the patient had chronic liver disease (liver cirrhosis) and Hashimoto's thyroiditis, both of which (9-11) are known to be associated with PAH. IFN may therefore have acted as the trigger for the development of PAH and/or worsening of asymptomatic $\mathrm{PAH}$ in our patient.

No treatment strategy for IFN-induced PAH has yet been established, due to a lack of evidence. The prognosis of IFN-induced PAH is usually poor, despite the discontinuation of IFN and administration of pulmonary vasodilators (8). A delay in the diagnosis and administration of PAH-specific medications may be associated with a worse outcome. In this case, the discontinuation of the IFN and 
early PAH-specific combination therapy may account for the successful treatment of IFN-induced PAH.

POPH has been reported in approximately 6-9\% of patients with advanced liver disease, and a higher incidence is shown in patients with HCV-related cirrhosis (12). In addition, HIV and HCV coinfections are known to increase the risk of PAH compared with HIV monoinfection. Several experimental studies have also demonstrated that HCV activates the STAT3 axis, which plays an important role in the pathogenesis of PAH $(13,14)$.

In conclusions, the vertically transmitted longstanding chronic HCV infection itself might have been associated with the development of asymptomatic PAH before IFN therapy in this case. Unfortunately, echocardiography was not performed before the IFN therapy. The present case had multiple PAH risk factors-namely liver cirrhosis, a chronic HCV infection, Hashimoto's thyroiditis, and female gender. We postulate that the IFN may have triggered the acute worsening of PAH via the activation of ET-1 and CXCL 10 and modulation of the immune response. All of these risk factors and triggers may have contributed to the development of PAH by interacting with each other (Fig. 3). Clinicians should be alerted to these potential risk factors for PAH exacerbation and should perform echocardiography for PH screening before and after the administration of IFN therapy.

The authors state that they have no Conflict of Interest (COI).

\section{References}

1. Hoeper MM, Bogaard HJ, Condliffe R, et al. Definitions and diagnosis of pulmonary hypertension. J Am Coll Cardiol 62: D42-D50, 2013.

2. Yuan JX, Rubin LJ. Pathogenesis of pulmonary arterial hypertension: the need for multiple hits. Circulation 111: 534-538, 2005.

3. Galiè N, Humbert M, Vachiery JL, et al. 2015 ESC/ERS Guidelines for the diagnosis and treatment of pulmonary hypertension: The Joint Task Force for the Diagnosis and Treatment of Pulmo- nary Hypertension of the European Society of Cardiology (ESC) and the European Respiratory Society (ERS) Endorsed by: Association for European Paediatric and Congenital Cardiology (AEPC), International Society for Heart and Lung Transplantation (ISHLT). Eur Heart J 46: 903-975, 2015.

4. Simonneau G, Gatzoulis MA, Adatia I, et al. Updated clinical classification of pulmonary hypertension. J Am Coll Cardiol 62: D34-D41, 2013.

5. George PM, Cunningham ME, Galloway-Phillipps $\mathrm{N}$, et al. Endothelin-1 as a mediator and potential biomarker for interferon induced pulmonary toxicity. Pulm Circ 2: 501-504, 2012.

6. Ko T, Hatano M, Nitta D, et al. A case of interferon- $\alpha$-induced pulmonary arterial hypertension after living donor liver transplantation. Heart Vessels 31: 1206-1208, 2016.

7. George PM, Oliver E, Dorfmuller P, et al. Evidence for the involvement of type I interferon in pulmonary arterial hypertension. Circ Res 114: 677-688, 2014.

8. Savale L, Sattler C, Gunther S, et al. Pulmonary arterial hypertension in patients treated with interferon. Eur Respir J 44: 16271634, 2014.

9. Satoh M, Aso K, Nakayama T, et al. Autoimmune thyroid disease in children and adolescents with idiopathic pulmonary arterial hypertension. Circ J 74: 371-374, 2010.

10. Chu JW, Kao PN, Faul JL, Doyle RL. High prevalence of autoimmune thyroid disease in pulmonary arterial hypertension. Chest 122: 1668-1673, 2002.

11. Li JH, Safford RE, Aduen JF, Heckman MG, Crook JE, Burger CD. Pulmonary hypertension and thyroid disease. Chest 132: 793797, 2007.

12. Chen HS, Xing SR, Xu WG, et al. Portopulmonary hypertension in cirrhotic patients: Prevalence, clinical features and risk factors. Exp Ther Med 5: 819-824, 2013.

13. Paulin R, Courboulin A, Meloche J, et al. Signal transducers and activators of transcription-3/pim1 axis plays a critical role in the pathogenesis of human pulmonary arterial hypertension. Circulation 123: 1205-1215, 2011.

14. Gong G, Waris G, Tanveer R, Siddiqui A. Human hepatitis C virus NS5A protein alters intracellular calcium levels, induces oxidative stress, and activates STAT-3 and NF-kappa B. Proc Natl Acad Sci U S A 98: 9599-9604, 2001.

The Internal Medicine is an Open Access article distributed under the Creative Commons Attribution-NonCommercial-NoDerivatives 4.0 International License. To view the details of this license, please visit (https://creativecommons.org/licenses/ by-nc-nd/4.0/).

(C) 2017 The Japanese Society of Internal Medicine http://www.naika.or.jp/imonline/index.html 